Table 1. Characteristics of the psoriasis cohort starting exclusively TNFi or methotrexate

\begin{tabular}{lccc}
\hline & $\begin{array}{c}\text { Incident PsA } \\
\mathrm{n}=35\end{array}$ & $\begin{array}{c}\text { PsA negative } \\
\mathrm{n}=119\end{array}$ & p-value \\
\hline $\begin{array}{l}\text { Treatment [n (\%)] } \\
\text { TNFi }\end{array}$ & $18(51.4)$ & $51(42.9)$ & 0.37 \\
Methotrexate & $17(48.6)$ & $68(57.1)$ & \\
Sex [n (\%)] & & & 0.24 \\
Female & $21(60.0)$ & $58(48.7)$ & \\
Male & $14(40.0)$ & $61(51.3)$ & \\
Age [median (IQR)] & $47.0(39.4,59.7)$ & $48.9(35.3,61.7)$ & 0.71 \\
Pso manifestations [n (\%)] & & & \\
Nail pitting & $27(77.1)$ & $51(42.9)$ & $<0.01$ \\
Scalp psoriasis & $31(88.6)$ & $105(89.0)$ & 0.95 \\
Inverse psoriasis & $14(40.0)$ & $37(31.09)$ & 0.33 \\
BSA [median (IQR)] & $6(3,15)$ & $12(5,22)$ & 0.06 \\
BMI [median (IQR)] & $31.7(25.9,40.4)$ & $29.1(26.3,34.7)$ & 0.30 \\
Therapy duration (years) & & & \\
TNFi [median (IQR)] & $4.38(1.34,8.13)$ & $2.26(0.76,5.82)$ & 0.29 \\
Methotrexate [median (IQR)] & $2.44(0.06,3.44)$ & $0.94(0.27,2.39)$ & 0.43 \\
& &
\end{tabular}

Disclosure of Interests: Noah Lininger: None declared, Sarah Siegel: None declared, Sonam Kiwalkar: None declared, Kevin Winthrop Grant/research support from: Bristol-Myers Squibb, Consultant of: AbbVie, Bristol-Myers Squibb, Eli Lilly, Galapagos, Gilead, GSK, Pfizer Inc, Roche, UCB, Alex Ortega Loayza Consultant of: Adviser board for Janssen, Atul Deodhar Grant/research support from: AbbVie, Eli Lilly, GSK, Novartis, Pfizer, UCB, Consultant of: AbbVie, Amgen, Boehringer Ingelheim, Bristol Myer Squibb (BMS), Eli Lilly, GSK, Janssen, Novartis, Pfizer, UCB, Speakers bureau: AbbVie, Amgen, Boehringer Ingelheim, Bristol Myer Squibb (BMS), Eli Lilly, GSK, Janssen, Novartis, Pfizer, UCB DOI: 10.1136/annrheumdis-2020-eular.4983

\section{FRI0556 INCREASED RISK OF MORTALITY AND CANCER IN SYSTEMIC LUPUS ERYTHEMATOSUS: RESULTS FROM A LUPUS COHORT STUDY FROM 1998 TO 2015}

G. Y. Ahn ${ }^{1}$, J. Lee ${ }^{2}$, J. M. Shin ${ }^{3}$, Y. K. Lee ${ }^{3}$, J. H. Kim¹, G. G. Song ${ }^{1}$, M. K. Kim ${ }^{4}$ S. C. Bae ${ }^{2,3} .{ }^{1}$ Korea University Guro Hospital, Division of Rheumatology, Department of Internal Medicine, Seoul, Korea, Rep. of (South Korea); ${ }^{2}$ Hanyang University Institute for Rheumatology Research, Seoul, Korea, Rep. of (South Korea); ${ }^{3}$ Hanyang University Hospital for Rheumatic Disease, Department of Rheumatology, Seoul, Korea, Rep. of (South Korea); ${ }^{4}$ College of Medicine, Hanyang University, Department of Preventive Medicine, Seoul, Korea, Rep. of (South Korea)

Background: Systemic lupus erythematosus (SLE) is a chronic systemic autoimmune inflammatory disease with increased risk for mortality and cancers possibly because of the effects of systemic inflammation and immunodeficiency due to disease itself and/or cytotoxic agents for SLE management. Although there has been improvement in the prognosis of SLE over decades with the treatment advance including standardized treatment strategy for lupus nephritis and less cytotoxic agents, the improvement also is fixed nowadays.

Objectives: In this study, we we are to investigate the mortality and cancer of SLE patients in a longitudinal SLE cohort and compare the morality ratio and incidence of cancer with general population over time.

Methods: This study was conducted in Hanyang BAE lupus cohort during the period of 1998 to 2015. Mortality data and malignancy data were derived in connection with data from the Korean National Statistics Office and the Korea Central Incidence Database, respectively. The Standardized Mortality Ratio (SMR) and Standardized Incidence Ratio (SIR) was estimated yearly by dividing the observed number deaths/cancers by the expected number of deaths/cancers of age- and sex- matched general population from matched year.

Results: Mortality data were available in 1284 patients and total 71 deaths were observed. The most common cause of death was SLE itself $(52.1 \%)$ followed by infection $(18.3 \%)$, cerebrovascular disease $(8.5 \%)$ and suicide $(7.0 \%)$. The total age and sex adjusted SMR was 3.4 [95\% Cl (Confidential Interval) 2.6-4.1]. When we conduct subgroup analysis by age, the sex-adjusted SMR was significantly increased in young and middle aged adult patients: the SMR in patients younger than 20 was 12.2 , but it was not significant due to the small number of young patients (observed death 3 , expected death $0.3,95 \% \mathrm{Cl} 0-26.0$ ). The adjusted SMR in patients aged 20-39, aged 40-59 and aged over 60 were 9.8 (observed death 35 , expected death $4.8,95 \%$ Cl 6.5-13.0), 3.7 (observed death 24 , expected death $11.5,95 \% \mathrm{Cl} 2.2-5.2$ ), and 1.0 (observed death 9, expected death $10.3,95 \% \mathrm{Cl} 0.3-1.6)$, respectively. Compared with alive patients, died patients had more serositis and more neurologic disorder according to American
College of Rheumatology classification criteria for SLE despite the shorter observational period (5.6 years vs. 9.4 years).

Malignancy data were available in 1,020 patients and 56 primary cancers were diagnosed. Solid tumor was developed in 51 patient and hematologic malignancy was developed in 5 patients ( 3 non-Hodgkin's lymphoma, 1 solitary plasmacytoma and 1 acute lymphoblastic leukemia). Thyroid cancer was the most common solid cancer (24 patients) followed by colorectal (5 patients), breast (4 patients), cervical cancer (4 patients) and hepatocellular carcinoma (3 patients). The total age and sex adjusted SIR was 1.1 (95\% $\mathrm{Cl}$ 0.8-1.4).

Conclusion: Patients with SLE had higher risk of mortality than general population and the younger patients had the higher risk of mortality. The leading cause of death was SLE itself followed by infection and cerebrovascular disease. The risk for cancer in patient with SLE was similar with that of general population.

Disclosure of Interests: None declared

DOI: 10.1136/annrheumdis-2020-eular.2557

FRI0557

\section{IN INDIVIDUALS AT-RISK OF RHEUMATOID} ARTHRITIS, ULTRASOUND BONE EROSIONS AT THE V METATARSOPHALANGEAL JOINTS ARE THE MOST PREDICTIVE FOR THE DEVELOPMENT OF CLINICAL ARTHRITIS.

A. DI Matteo ${ }^{1,2}$, K. Mankia $^{1}$, L. Duquenne ${ }^{1}$, E. Cipolletta ${ }^{2}$, R. Wakefield ${ }^{1}$, J. Nam ${ }^{1}$, L. Garcia-Montoya ${ }^{1}$, P. Emery ${ }^{1} .{ }^{1}$ Leeds Institute of Rheumatic and Musculoskeletal Medicine, Leeds, United Kingdom; ${ }^{2}$ Polytechnic University of Marche, Rheumatology Unit, "Carlo Urbani” Hospital, Jesi, Ancona, Italy, Department of Clinical and Molecular Sciences, lesi, Italy

Background: While the central role of bone erosions in the pathogenesis and diagnosis of patients with rheumatoid arthritis (RA) is widely recognized their prevalence, pattern, and relationship with subclinical synovitis in individuals at-risk of RA (positive autoantibodies without clinical arthritis) is not well understood.

Objectives: To investigate, in individuals at-risk of RA, the prevalence and distribution of ultrasound (US) bone erosions, their correlation with subclinical synovitis at joint level, and their association with the development of inflammatory arthritis (IA).

Methods: Baseline US scans of $2^{\text {nd }}$ generation anti-cyclic citrullinated peptide (CCP) positive at-risk subjects with musculoskeletal symptoms (without clinica arthritis) taking part in the Leeds CCP study were analyzed. The presence of bone erosions was evaluated in the classic sites for RA damage: the II and V metacarpophalangeal (MCP) joints, and the $\mathrm{V}$ metatarsophalangeal (MTP) joints ${ }^{1}$. US synovitis was defined as synovial hypertrophy $(\mathrm{SH}) \geq 2$ or $\mathrm{SH} \geq 1+$ power Doppler signal $\geq 1^{2}$. Only subjects with $\geq 1$ follow-up visit were included in the progression analysis $(n=400)$. Progression to IA was defined as the development of clinical synovitis in $\geq 1$ one joint.

Results: US bone erosions: prevalence, distribution, and association with subclinical synovitis

A total of 2514 joints, in 419 subjects were evaluated.

Bone erosions were found in $\geq 1$ joint in $41 / 419$ subjects $(9.8 \%$ ), in $55 / 2514$ joints (2.2\%). The prevalence of bone erosions was significantly higher in the V MTP than

Table 1.

\begin{tabular}{|c|c|c|c|c|c|c|}
\hline & \multicolumn{2}{|c|}{ Ever } & \multicolumn{2}{|c|}{ At 1 year } & \multicolumn{2}{|c|}{ At 3 years } \\
\hline & $\mathrm{HR}(95 \% \mathrm{Cl})$ & $P$ value & HR (95\%Cl) & $P$ value & $\mathrm{HR}(95 \% \mathrm{Cl})$ & $\begin{array}{c}P \\
\text { value }\end{array}$ \\
\hline $\begin{array}{l}\text { Presence of bone erosion } \\
\text { in } \geq 1 \text { joint (any joint) }\end{array}$ & $\begin{array}{c}3.98 \\
(1.82-8.7)\end{array}$ & $<0.01$ & $\begin{array}{c}3.57 \\
(1.7-7.5)\end{array}$ & $<0.01$ & $\begin{array}{c}3.48 \\
(1.63-7.4)\end{array}$ & $<0.01$ \\
\hline - in the II MCP joints & $\begin{array}{c}2.4 \\
(0.52-11.08)\end{array}$ & 0.26 & $\begin{array}{c}1.07 \\
(0.2-5.76)\end{array}$ & 0.94 & $\begin{array}{c}1.67 \\
(0.38-7.04)\end{array}$ & 0.5 \\
\hline - in the V MCP joints & $\begin{array}{c}1.37 \\
(0.06-31)\end{array}$ & 0.85 & $\begin{array}{c}0 \\
(\mathrm{~N} / \mathrm{A})\end{array}$ & 1 & $\begin{array}{c}0 \\
(\mathrm{~N} / \mathrm{A})\end{array}$ & 1 \\
\hline - in the V MTP joints & $\begin{array}{c}4.79 \\
(1.97-11.63)\end{array}$ & $<0.01$ & $\begin{array}{c}5.23 \\
(2.32-11.8)\end{array}$ & $<0.01$ & $\begin{array}{c}5.43 \\
(2.28-12.92)\end{array}$ & $<0.01$ \\
\hline $\begin{array}{l}\text { Presence of bone erosion } \\
\text { and synovitis in the same } \\
\text { joint (any joint) }\end{array}$ & $\begin{array}{c}3.9 \\
(1.19-12.77)\end{array}$ & 0.02 & $\begin{array}{c}6.03 \\
(2.07-17.55)\end{array}$ & $<0.01$ & $\begin{array}{c}3.91 \\
(1.29-11.85)\end{array}$ & 0.02 \\
\hline $\begin{array}{l}\text { Presence of bone erosion } \\
\text { and synovitis in the same } \\
\text { V MTP joint }\end{array}$ & $\begin{array}{c}5.08 \\
(1.37-18.9)\end{array}$ & 0.02 & $\begin{array}{c}7.03 \\
(2.28-21.71)\end{array}$ & $<0.01$ & $\begin{array}{c}4.89 \\
(1.48-16.19)\end{array}$ & $<0.01$ \\
\hline $\begin{array}{l}\text { Presence of bone erosion } \\
\text { in }>1 \text { joint (any joint) }\end{array}$ & $\begin{array}{c}10.63 \\
(1.87-60.42)\end{array}$ & $<0.01$ & $\begin{array}{c}5.68 \\
(1.66-19.5)\end{array}$ & $<0.01$ & $\begin{array}{c}7.26 \\
(1.67-31.66)\end{array}$ & $<0.01$ \\
\hline
\end{tabular}

IA free survival rates are showed in Figures 1 and 2 . 
in the MCP joints ( $p<0.01)$. They were detected in 42V MTP (31 subjects; $7.4 \%)$, in 10 II MCP (10 subjects; $2.4 \%$ ), and in $3 \mathrm{~V} \mathrm{MCP} \mathrm{(3} \mathrm{subjects;} 0.7 \%$ ) joints. US synovitis was detected in $22 / 55$ joints (40\%) with bone erosions, in $17 / 41$ subjects $(42 \%)$. It was found in $48.6 \%$ of the V MTP, in $20 \%$ of the II MCP and in none of the $\mathrm{V}$ MCP joints with bone erosions. A significant correlation between bone erosions and synovitis in the same joint was detected (Cramer's $V=0.22, p<0.01$ ).

Seven out of the 55 joints $(12.7 \%)$ with bone erosions were tender on physical examination: $14.3 \%$ of the V MTP, $10 \%$ of the II MCP, and none of the V MCP joints.

US bone erosions: predicting development of IA

A total of 122 subjects (30.5\%) developed IA (median follow-up: 301 days, IQR 112-721). The hazard ratios of the US findings for the development of IA (adjusted for age, sex, smoking, anti-CCP and rheumatoid factor titer) are reported in Table 1.

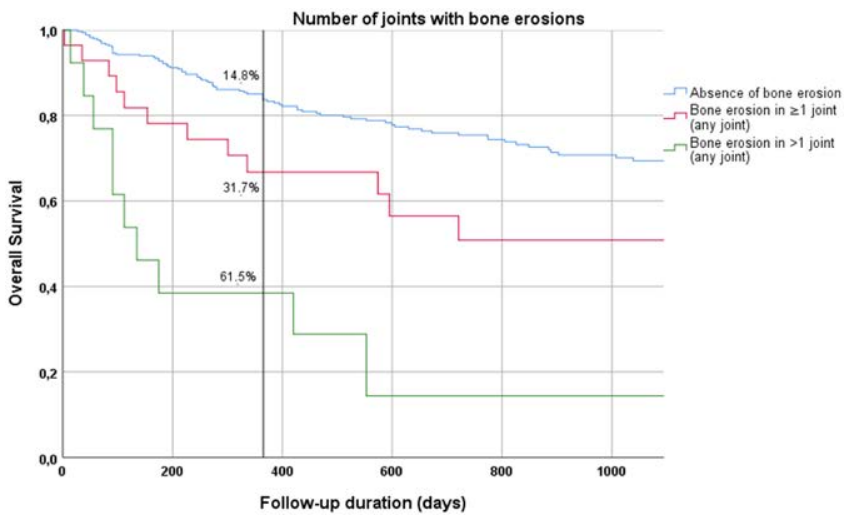

Figure 1.

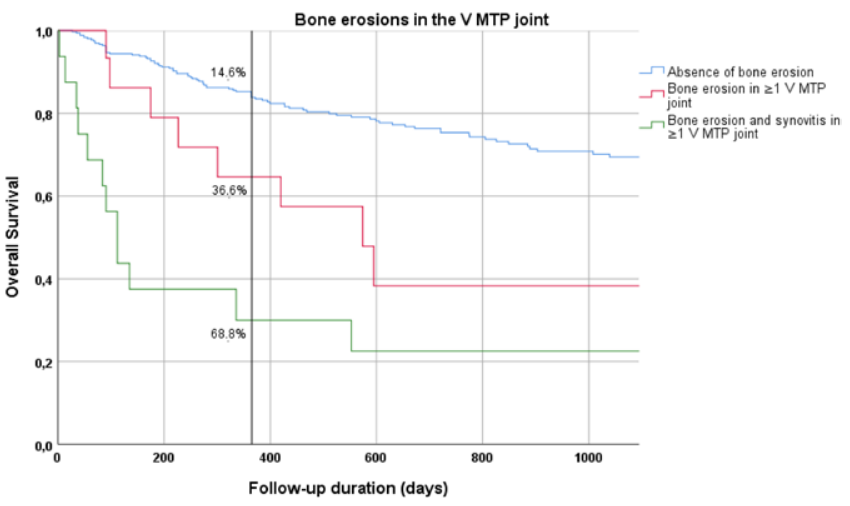

Figure 2.

Conclusion: The feet appear to be an early site for damage in individuals at-risk of RA. US bone erosions were mainly detected in asymptomatic joints, but frequently in association with subclinical synovitis. In individuals at-risk of RA, bone erosions in the V MTP joints are more predictive than in the hands (II and V MCP joints) for the development of IA.

References:

[1] Zayat AS, et al. Ann Rheum Dis. 2015;

[2] D’Agostino, et al. RMD Open. 2017;

Disclosure of Interests: Andrea Di Matteo Grant/research support from: the publication was conducted while Dr. Di Matteo was an ARTICULUM fellow, Kulveer Mankia: None declared, Laurence Duquenne: None declared, Edoardo Cipolletta: None declared, Richard Wakefield Speakers bureau: Novartis, Janssen, GE, Jacqueline Nam: None declared, Leticia Garcia-Montoya: None declared, Paul Emery Grant/research support from: AbbVie, Bristol-Myers Squibb, Merck Sharp \& Dohme, Pfizer, Roche (all paid to employer), Consultant of: AbbVie (consultant, clinical trials, advisor), Bristol-Myers Squibb (consultant, clinical trials, advisor), Lilly (clinical trials, advisor), Merck Sharp \& Dohme (consultant, clinical trials, advisor), Novartis (consultant, clinical trials, advisor), Pfizer (consultant, clinical trials, advisor), Roche (consultant, clinical trials, advisor), Samsung (clinical trials, advisor), Sandoz (clinical trials, advisor), UCB (consultant, clinical trials, advisor)

DOI: 10.1136/annrheumdis-2020-eular.784

\section{FRI0558 \\ PREGNANCY OUTCOMES IN PATIENTS WITH AXIAL SPONDYLOARTHRITIS - A FIRST JOINT ANALYSIS OF A EUROPEAN COLLABORATION OF PREGNANCY REGISTERS}

Y. Meißner $^{1}$, N. Costedoat-Chalumeau ${ }^{2,3}$, F. Förger $^{4}$, D. Goll ${ }^{5}$, A. Moltó $^{2}$, R. Özdemir ${ }^{5}$, M. Wallenius ${ }^{6,7}$, A. Strangfeld ${ }^{1}$, R. Fischer-Betz ${ }^{8}{ }^{1}$ Deutsches Rheuma-Forschungszentrum, Berlin, Germany; ${ }^{2}$ AP-HP, Cochin Hospital, Paris, France; ${ }^{3}$ Université de Paris, Paris, France; ${ }^{4}$ Inselspital University Hospital Bern, Bern, Switzerland; ${ }^{5}$ Patient representative, Berlin, Germany; ${ }^{6}$ Norwegian University of Science and Technology, Trondheim, Norway; ${ }^{7}$ University Hosital, Trondheim, Norway; ${ }^{8}$ University Clinic Duesseldorf, Düsseldorf, Germany

Background: Axial spondyloarthritis (axSpA) can affect women in their childbearing age. But data on pregnancy in axSpA patients are mainly retrospective and highly heterogeneous [1].

Objectives: The aim of this analysis was to investigate pregnancy outcomes and health of live born children in women with axSpA in four prospective cohort studies.

Methods: Data of European pregnancy registries that collaborate in the European Network of Pregnancy Registries in Rheumatology (EuNeP) were analysed: EGR2 (France), RePreg (Switzerland), RevNatus (Norway) and Rhekiss (Germany). Eligible women had a diagnosis of axSpA and a pregnancy outcome reported until June-September 2019. Data were analysed descriptively by every registry and provided to the coordinating centre.

Results: A total of 328 pregnancies in 288 women were investigated. Mean age of patients ranged from 31 to 33 years. Disease duration (3-8 years) and proportion of patients with a positive HLA-B27 (64-74\%) varied (Table 1). The axSpA diagnosis was either classified by ASAS criteria (fulfilment in EGR2: 93\%, RePreg: 65\%, RevNatus: $86 \%$ ) or by ASAS criteria for axial/ peripheral SpA (Rhekiss: $81 / 34 \%$ ). Rates for preterm birth were $\leq 5 \%$, and congenital malformations were reported in 4 out of 287 neonates (Table 2).

Table 1. Maternal and disease characteristics

\begin{tabular}{lcccc}
\hline & EGR2 (FR) & RePreg (CH) & RevNatus (NO) & Rhekiss (DE) \\
\hline \# Pregnancies & 45 & 31 & 160 & 92 \\
\# Patients & 44 & 31 & 125 & 88 \\
Age in years & $32.0 \pm 4.2$ & $31.4 \pm 4.0$ & $30.5 \pm 4.5$ & $33.2 \pm 4.4$ \\
Disease duration in years & $6.0 \pm 5.6$ & $7.7 \pm 4.6$ & $3.2 \pm 3.3$ & $6.2 \pm 5.3$ \\
HLA-B27 positive & $26(66.7)$ & $23(74.2)$ & $79(71.2)$ & $54(73.0)$ \\
Pre-gestational diabetes & 0 & 0 & $1(0.6)$ & $1(1.4)$ \\
IBD & 0 & 0 & $4(2.6)$ & $5(7.2)$ \\
Uveitis & 0 & 0 & $3(1.9)$ & $3(4.3)$ \\
BMl & $26.5 \pm 4.8$ & $22.6 \pm 2.5$ & $24.4 \pm 4.3$ & $23.4 \pm 4.3$ \\
\hline
\end{tabular}

Results as mean \pm SD or number (percentage)

Table 2. Pregnancy characteristics, obstetric and neonatal outcomes

\begin{tabular}{|c|c|c|c|c|}
\hline & EGR2 (FR) & RePreg (CH) & RevNatus (NO) & Rhekiss (DE) \\
\hline WGA at $1^{\text {st }}$ visit in pregnancy & $11.9 \pm 8.2$ & $19.7 \pm 9.4$ & $12.9 \pm 5.7$ & $13.4 \pm 5.4$ \\
\hline Patients with 1 pregnancy & $43(95.5)$ & $31(100.0)$ & $101(80.8)$ & $84(95.5)$ \\
\hline $\begin{array}{l}\text { Primigravidae } \\
\text { Adverse events of interest }\end{array}$ & $18(40.0)$ & $15(48.4)$ & $47(29.4)$ & $37(45.1)$ \\
\hline Preeclampsia & $1(4.4)$ & 0 & $4(2.6)$ & 0 \\
\hline Gestational diabetes & $4(8.9)$ & $2(6.5)$ & n.a. & $5(6.2)$ \\
\hline Pregnancy outcomes & & & $\begin{array}{c}\text { (5 Outcomes } \\
\text { missing) }\end{array}$ & $\begin{array}{c}\text { (1 Outcome } \\
\text { missing) }\end{array}$ \\
\hline Elective termination & $1(2.2)$ & 0 & $2(1.3)$ & 0 \\
\hline Miscarriage (<WGA 20) & $2(4.4)$ & 0 & $13(8.4)$ & $4(4.4)$ \\
\hline Pregnancy loss >WGA 20 & $2(4.4)$ & 0 & 0 & 0 \\
\hline Live birth & $40(88.9)$ & $31(100.0)$ & $140(90.3)$ & 87 (95.6) \\
\hline Outcomes of live births & & & & \\
\hline \# Neonates, singleton pregn. & 40 & 30 & 139 & $78^{\$}$ \\
\hline $\begin{array}{l}\text { \# Neonates, multiple pregn. } \\
\text { Neonatal outcomes, only single- } \\
\text { ton pregnancies }\end{array}$ & 0 & 2 & 2 & 4 \\
\hline WGA at delivery & $39.1 \pm 1.2$ & $39.5 \pm 1.5$ & $38.9 \pm 2.3$ & $39.4 \pm 2.0$ \\
\hline Preterm birth & 0 & 0 & $6(4.3)$ & $4(5.4)$ \\
\hline Birth weight in $\mathrm{g}$ & $3253 \pm 395$ & $3314 \pm 519$ & $3446 \pm 526$ & $3377 \pm 522$ \\
\hline Congenital malformation & 0 & 0 & n.a." & $4(5.1)$ \\
\hline
\end{tabular}

Results as mean $\pm \mathrm{SD}$ or number (percentage). WGA: gestational age in weeks \#Malformations can be retrieved by national birth registry with a lag time of 2 years. \$Missing information for 7 infants. 